\title{
Study on the Key Characteristics of Regional Characteristics and Environmental Art Design
}

\author{
Guomin Huang
}

Wuchang Institute of Technology, Wuhan, Hubei, 430065

\author{
Keywords: Regional Characteristics, Environmental Art Design, Key Characteristics
}

\begin{abstract}
With the development of modern science and technology and the growing globalization of economy, the strong culture of economic power to suppress the development of regional culture, with regional characteristics of the culture gradually disappear. Globalization poses a challenge to traditional design theories and methods and affects the traditional environmental art design value system. In the face of globalization and homogenization of modernism, people are gradually aware of its unfavorable factors. Environmental art design exactly where to go, become a modern designer must face and think the reality of the problem. This paper attempts to explore how environmental art design reflects the regional characteristics in the context of global integration and cultural diversification, hoping to bring some new ideas and inspiration for environmental art design.
\end{abstract}

\section{Introduction}

In today's highly developed science and technology, economic globalization has led to the expansion of regional culture. Globalization affects the traditional environmental art design value system, so that the traditional design theory and methods are replaced by globalized emphasis on homogenization and homogenization of the design model. This article takes the architectural and landscape as the main research object. Contemporary architects in the traditional architectural culture theory and practice has done a lot of research and efforts, here also some of their research results and the theory of comparison and analysis, from various aspects of environmental art design in the geographical characteristics of the importance.

The concept of the region is mainly derived from the space, the region can be said to be a certain range of space within the general term. Geographical features all-encompassing, summed up the region, including the economy, humanities, science and technology and other elements, the birth of regional characteristics of human civilization is a sign of progress, but also the only way to form regional characteristics. There are natural factors in the geographical space, and then by natural factors to create a unique human characteristics, for example, the natural characteristics of the climate will affect the people's living habits and behavior; water temperature factors will affect the overall structure of the region. Geographical features have distinct characteristics, first, regional. Geographical characteristics must be studied in a certain geographical area, such as the characteristics of our study of a region, must be limited to the region to start research. Second, the humanities. Human activities in a particular space area, in harmony with nature, will create a unique regional culture, these cultures must be different from other regions, which is unique regional culture. Third, comprehensive. When we analyze the geographical features, although it can be from the economic, humanities, science and technology and other aspects of the general discussion, but the geographical features of the elements far more than that, geographical features can make people think of a lot of things, and these complex and interrelated Things are necessary to create regional characteristics. 


\section{The Influence of Regional Features on Environmental Art Design}

In the context of geographical characteristics, environmental art design work will inevitably be affected, the impact comes from the geographical characteristics of the strong regional atmosphere and cultural spirit. The impact of regional characteristics in environmental art design, not only real objects, more spiritual and cultural connotations in which, this is the geographical characteristics of the environmental art design to bring the profound impact, it is to promote environmental art design On the basis of artistic approach, to achieve regional art integration and sublimation, so that with the regional characteristics of integration, to create a commendable works of art. Specifically, the geographical characteristics of environmental art design impact is mainly reflected in the following aspects:

For the environmental art design, the most profound, creative, but also with regional characteristics of the design work, and both are combined with the case of the birth of the region. Each area will have its own unique characteristics, environmental art design work is not a simple design work, its art can effectively play out, completely see the geographical characteristics can be integrated into them. The distinctive regional characteristics of various regions of our country can add many cultural elements and cultural backgrounds to the environmental art design, and give designers a rich design inspiration to create a commendable environmental art design work. For example, such a historical city of Beijing and cultural ancient capital, environmental art and design to be more biased towards classical, and as China's capital, its regional characteristics and full of fashion and fashion, so designers should combine classical and fashion, For the Beijing to make environmental art design. It is precisely because the environmental art design is inseparable from the geographical characteristics, so any of the environmental art design works must have the shadow of geographical features, because the existence of features, making the environmental art design is more ingenuity unique, unique, rich regional characteristics.

In the past, environmental art design practices are changing and updating, the traditional environmental art design approach is simply a discussion of environmental design and design, the environment of the installation, color and other content to explore, to expand and design. Therefore, the traditional environmental art design approach is relatively simple, can not meet the current aesthetic needs of environmental art, but also for the rich cultural connotation, the economic level of the city, the environmental art design must keep pace with the times, and culture , Economic and other elements of the combination of innovative design techniques. Therefore, the introduction of geographical features into the environmental art design, it is equivalent to the cultural, economic and other elements into the design, the designer in the development of environmental art design, not only the elements of the environment itself can be designed, but also can be combined with the city The cultural heritage, customs, economic characteristics of the analysis, these elements of the scientific integration into the design work, you can enrich the design of the performance techniques, to create more loved and creative design works.

\section{Regional Characteristics of Traditional Chinese Environmental Art}

Chinese traditional architecture and garden pay attention to harmony between man and nature, emphasizing the interaction with the natural environment and against the background. People pursue the actual situation echo, twists and turns to achieve harmony between man and nature, seamless realm. China 's history and culture has a long history, thousands of years of culture on the impact of environmental art can be described as deep, which Confucianism, Taoism, Buddhist philosophy, ethics, aesthetics, religious thought of the greatest impact on environmental art. China's traditional garden design ideas of the fundamental characteristics of nature, garden art in nature is to have a natural reason, the natural interest, rather than artificial work. Landscape in the garden is the generalization and improvement of nature, and thus in accordance with the direction of the rocks and the flow of water to organize the flow of the most important landscape. Of course, the garden can not be reproduced from the scale of the natural beauty of the landscape, can only imitate a part 
of the natural landscape or abstract to show the natural landscape, "landscape beauty" is always the eternal theme of traditional Chinese gardens. Whether it is a royal garden or a private garden, all in the performance of landscape beauty, such as the Summer Palace is one of the masterpiece.

Chinese traditional literature, art, broad and profound, has a long history, the impact of the garden is very far-reaching. Chinese classical gardens are full of poetic painting, and poetry, painting art has a very close relationship, garden, literature, painting mutual influence mutual development. China's landscape painting, pay attention to freehand, emphasizing mood, is the so-called "foreign division good fortune, in the heart." The painters observe the beauty of nature, the garden from the conception of ideas until the specific techniques, a comprehensive reference to the painting to enhance its artistic expression, is the landscape of the real three-dimensional form of reproduction. For example, in the spatial division, the use of various elements of the landscape in the twists and turns to form a progressive spatial sequence. As the poetic style to suppress the first Yang or want to advance the same, the division can not be fragmented, the combination should pay attention to open and close together, change orderly, strong sense of hierarchy, the sequence of the general must have prelude, starting, theme, climax , Turning, ending, forming a rich and colorful content, the overall harmony of the continuous flow of space.

The traditional Chinese architectural culture is a unique cultural resource rooted in the local area. It is complementary to the traditional cultural advantages of the rest of the world and is an indispensable part of the world cultural diversity. Residential as a type of building, it is subject to a certain natural environment, but also subject to a certain social and cultural background. Because it is widely distributed, and with the people of all nationalities life, production is closely related, so it has obvious regional characteristics and strong national characteristics. Such as Beijing's courtyard, southwest of the Diaojiaolou, the northern Shaanxi cave, Minnan's earthen, Qinghai Zhuangzhuang, Guangxi's mahogany, grassland yurts, plateau stone towers, Dai's bamboo, Dali and Lijiang's "three Square one wall "," four five patio "and so on, are China's rich formal cultural heritage of residential buildings. The diverse forms and characteristics of Chinese dwellings show complex interactions and influences between many factors. Due to the different geographical and climatic conditions, the residential buildings in the material, tectonic technology, and methods, environmental defense requirements, economic and other aspects of the obvious differences in religious factors on the architectural form also had a great impact.

\section{Regional Features and Age Aesthetics}

China has its own history and culture, there are very rich architectural language, the Chinese people have traditional construction experience, should learn from nutrition, in their own way to save this memory. Of course, you can learn from others, but must not copy. The architect should be at a deeper level, the synthesis of the human nature, the original past to continue. Architecture is the history of the whole living space, in different times to get different performance. We emphasize in the design of the overall design of environmental art is relative to the big planning in terms of large to the whole country, the whole nation, small to the whole city, the whole village.

The correct attitude towards the tradition is to see both the traditional and the historical side, but also the traditional universality and transcendence. From the process of historical development, the traditional culture of any nation in the world contains both the essence and the dross. Vigorously develop the new culture embodies the spirit of the times, we must inherit and carry forward the fine traditional culture, it is necessary to abandon the cultural dross. "Take its essence" must not be treated with contemporary utilitarianism view of national folk culture, but must respect the national folk culture of mass, extensive, the existence of rationality, on this basis, careful and scientific treatment.

Respect for the natural and cultural environment in which the building is located, and only from the specific geographical environment and cultural conditions, deepen the understanding of the deep nature and the law of the building environment in order to form an organic unity of the three buildings. The natural attributes of the area are the most important factors of geographical features. In general, the natural conditions around are hard to change. The difference in geographical 
characteristics leads to the diversity of regional architecture. Such as the southwest region more rain, hot and humid, the building needs opening transparent, arcade shelter, corridor connection. As the local vegetation varieties, natural rich colors, most of the buildings using natural color, pink wall brown column, green tile window, elegant and bright. While the northern architectural style of vigorous dignified, it is due to its practical function of a need for insulation. At the same time the winter green vegetation, natural color monotonous, architectural decoration color is warm, red wall Zhu door, yellow tile green window, contrast, the Forbidden City is the most significant representative. Yunnan bamboo floor, Jiangnan garden, Beijing courtyard each have its distinctive geographical characteristics. Architects do not just stay on the surface to study the traditional architectural culture, to fully understand the local residents living habits, traditional culture, in order to dig out the architectural form of architectural culture outside the connotation.

\section{Conclusion}

With the deepening of contemporary regional architectural research and creative activities, how to deal with the relationship between globalization and regional architectural culture has become an important issue in the development of Chinese architectural creation. In the global diversified environment, the use of the concept of regional characteristics of the deep excavation of environmental art design is a development of the road. The use of geographical features to carry out environmental art design is not blind imitation and copying, in the current design areas there are still some problems and shortcomings. How to make the design of both people to meet the function and can give people the spirit of the sustenance is that we should focus on the design considerations. Correct understanding and inheritance of traditional Chinese architectural culture should not be a simple imitation, collage and borrowing of predecessors' forms, styles and archetypes, thus putting "nationalism" and "tradition".

\section{References}

[1] Zheng Dongjun, Yu Li. Contemporary regional architectural culture analysis [J]. Chinese and foreign architecture. 2005 (04)

[2] Qin Hongling. Inheritance of traditional Chinese architectural culture [J]. Chinese and foreign architecture. 2005 (04)

[3] Lin Qing, Wang Xiangrong. Regional characteristics and landscape form [J]. Chinese Garden. 2005 (06)

[4] Shen Kening. Criticism of regionalism [J]. Architects. 2004 (05)

[5] Zhou Chang. Reconsideration of local traditional architectural culture [J] .Journal of Architecture 2000 (01)

[6] Wu Liangyong. The turn of the century to look forward to the future of architectureInternational Association for the 20th session of the General Assembly report [J]. Journal of Architecture. 1999 (08) 